\title{
ST. JUDE MEDICAL VALVE PROSTHESIS: AN ANALYSIS OF LONG-TERM OUTCOME AND PROGNOSTIC FACTORS
}

\author{
L-F. Debétaz, MD \\ P. Ruchat, $\mathrm{MD}^{\mathrm{b}}$ \\ M. Hurni, MD ${ }^{\mathrm{b}}$ \\ A. Fischer, $\mathrm{MD}^{\mathrm{b}}$ \\ F. Stumpe, $\mathrm{MD}^{\mathrm{b}}$ \\ H. Sadeghi, $\mathrm{MD}^{\mathrm{b}}$ \\ G. van Melle, $\mathrm{PhD}^{\mathrm{c}}$ \\ J-J. Goy, MD
}

\begin{abstract}
Between 1979 and 1984, 321 patients received 354 St. Jude Medical prostheses (194 aortic, 94 mitral, 1 tricuspid, and 32 multiple valve replacements). Follow-up was $96 \%$ complete (2967 patient-years; mean 9.5 years per patient). Actuarial event-free rates at $\mathbf{1 0}$ years and linearized rates (in parentheses) of late complications were as follows: embolism, $\mathbf{8 5 . 0 \%} \pm \mathbf{2 . 3 \%}(2.3 \%$ per patient-year); anticoagulant-related hemorrhage, $\mathbf{7 4 . 8 \%} \pm \mathbf{2 . 7 \%}(3.3 \%$ per patient-year); cerebrovascular accident, $81.8 \% \pm$ $2.5 \%$ (2.6\% per patient-year); prosthesis thrombosis, $98.5 \% \pm 0.7 \%(0.1 \%$ per patient-year); endocarditis, 97.2\% $\pm 1.1 \%(0.4 \%$ per patient-year); prosthesis dysfunction, $97.1 \% \pm 1.0 \%(0.4 \%$ per patient-year); hemolytic anemia, $98.5 \% \pm 0.7 \%(0.1 \%$ per patient-year $)$; reoperation, $97.4 \% \pm 1.0 \%$ (0.4\% per patient-year); overall mortality, $63.3 \% \pm 2.7 \%(4.2 \%$ per patientyear); and valve-related death (including sudden death), 84.7\% $\pm 2.2 \%$ (1.4\% per patient-year). Independent preoperative risk factors were as follows: (1) for embolism, cardiac failure as indication for operation and history of prior systemic embolism; (2) for cerebrovascular accidents, the same two factors and age; (3) for endocarditis, diabetes, chronic alcoholism, and aortic valve replacement; (4) for overall mortality, age, ejection fraction (or cardiac index or cardiothoracic index), chronic alcoholism, and history of systemic embolism; and (5) for valve-related death, chronic alcoholism, degenerative cause of valve disease, and prosthetic diameter 23 mm or smaller. Ninety percent of survivors were in New York Heart Association functional class I or II at the end of follow-up. In conclusion, this study confirms the excellent durability of the St. Jude Medical valve and the remarkable functional benefit for the majority of the patients. However, prosthesis-related complications are still common, particularly for small-diameter prostheses. Outcome is strongly related to the patient's preoperative cardiac condition and to the adequacy of anticoagulation control. (J Thorac Cardiovasc Surg 1997;113:134-48)
\end{abstract}

$T^{\mathrm{h}}$ he St. Jude Medical valve is a bileaflet, lowprofile, central flow design prosthesis known for its excellent hemodynamic properties. Follow-up studies have also demonstrated its mechanical durability, ${ }^{1-18}$ and only anecdotal structural failures have been reported. ${ }^{2,19,20}$ Nevertheless, these stud-

From the Division of Cardiology, ${ }^{\mathrm{a}}$ the Service of Cardiothoracic Surgery, ${ }^{\mathrm{b}}$ and the Institute for Social and Preventive Medicine, ${ }^{\mathrm{c}}$ University Hospital, Lausanne, Switzerland.

Received for publication Jan. 24, 1996; revisions requested March 18, 1996; revisions received July 9, 1996; accepted for publication July 22, 1996.

Address for reprints: J-J. Goy, MD, Division of Cardiology, CHUV, CH-1011 Lausanne, Switzerland.

Copyright $\mathbb{C} 1997$ by Mosby-Year Book, Inc.

$0022-5223 / 97 \$ 5.00+0 \quad \mathbf{1 2 / 1 / 7 6 8 2 9}$ ies have also shown that, despite a thromboresistant pyrolytic carbon coating, anticoagulant therapy with its related risks is still required. In the present study, the incidence and preoperative determinants of every late complication are analyzed in patients followed up at least 10 years after the implantation of a St. Jude Medical prosthesis. Analysis of early events is also briefly presented.

\section{Patients and methods}

Patients. Between July 1979 and December 1984, 519 patients received at least one St. Jude Medical valve in our hospital. To get the most complete follow-up we only selected for study the patients living in Switzerland at the time of operation. Thus 321 patients were included who received 354 St. Jude Medical valves. Clinical data are shown in Table I. Previous valve operation had been done 
Table I. Patient data $(n=321)$

\begin{tabular}{|c|c|c|c|c|c|}
\hline & $A V R$ & $M V R$ & $T V R$ & Multiple VR & All \\
\hline No. of patients & 194 & 94 & 1 & 32 & 321 \\
\hline Age (mean $\pm \mathrm{SD})$ & $58 \pm 13$ & $57 \pm 11$ & 68 & $52 \pm 14$ & $57 \pm 13$ \\
\hline \multicolumn{6}{|l|}{ Sex } \\
\hline Male & $132(68.0 \%)$ & $41(43.6 \%)$ & - & $16(50.0 \%)$ & $189(58.9 \%)$ \\
\hline Female & $62(32.0 \%)$ & $53(56.4 \%)$ & 1 & $16(50.0 \%)$ & $132(41.1 \%)$ \\
\hline \multicolumn{6}{|l|}{ NYHA class } \\
\hline I & $17(8.8 \%)$ & $2(2.1 \%)$ & - & $1(3.1 \%)$ & $20(6.2 \%)$ \\
\hline II & $75(38.7 \%)$ & $29(30.9 \%)$ & 1 & $12(37.5 \%)$ & $117(36.5 \%)$ \\
\hline III & $68(35.0 \%)$ & $47(50.0 \%)$ & - & $15(46.9 \%)$ & $130(40.5 \%)$ \\
\hline IV & $34(17.5 \%)$ & $16(17.0 \%)$ & - & $4(12.5 \%)$ & $54(16.8 \%)$ \\
\hline \multicolumn{6}{|l|}{ Rhythm ECG } \\
\hline Sinusal & $174(89.7 \%)$ & $33(35.1 \%)$ & 1 & $13(40.6 \%)$ & $221(68.8 \%)$ \\
\hline $\mathrm{AF}$ & $18(9.3 \%)$ & $60(63.8 \%)$ & - & $18(56.3 \%)$ & $96(30.0 \%)$ \\
\hline Other & $2(1.0 \%)$ & $1(1.1 \%)$ & - & $1(3.1 \%)$ & $4(1.2 \%)$ \\
\hline \multicolumn{6}{|l|}{$\mathrm{CAD}$} \\
\hline Present & $36(18.6 \%)$ & $10(10.6 \%)$ & - & $4(12.5 \%)$ & $50(15.6 \%)$ \\
\hline Absent & $137(70.6 \%)$ & $77(81.9 \%)$ & 1 & $26(81.3 \%)$ & $241(75.1 \%)$ \\
\hline Unknown & $21(10.8 \%)$ & $7(7.5 \%)$ & - & $2(6.2 \%)$ & $30(9.3 \%)$ \\
\hline History of embolism & $15(7.7 \%)$ & $7(7.5 \%)$ & - & $1(3.1 \%)$ & $23(7.2 \%)$ \\
\hline $\begin{array}{l}\text { Cardiothoracic index } \\
\quad(\text { mean } \pm \text { SD) }\end{array}$ & $0.54 \pm 0.06$ & $0.56 \pm 0.07$ & 0.76 & $0.56 \pm 0.05$ & $0.55 \pm 0.07$ \\
\hline Emergency operation & $8(4.1 \%)$ & $6(6.4 \%)$ & - & - & $14(4.3 \%)$ \\
\hline
\end{tabular}

$T V R$, Tricuspid valve replacement; $S D$, standard deviation; $E C G$, electrocardiogram; $A F$, atrial fibrillation; $C A D$, coronary artery disease.

in 34 patients $(11 \%)$ and coronary artery bypass grafting in 2 patients $(0.6 \%)$. The characteristics of the pathologic valves are shown in Table II. Hemodynamic and angiographic preoperative data for aortic or mitral valvulopathy are shown in Table III. The first indication for operation was cardiac failure in 226 cases $(70.4 \%)$, chest pain in 16 $(5 \%)$, syncope in $20(6.2 \%)$, prosthesis dysfunction in 8 $(2.5 \%)$, recurrent emboli in $1(0.3 \%)$, and combination of two symptoms or more in $50(15.6 \%)$.

Surgical procedures. Operations were done with use of the standard technique of cardiopulmonary bypass with moderate hypothermia $\left(28^{\circ}\right.$ to $\left.32^{\circ} \mathrm{C}\right)$ and cold crystalloid cardioplegia combined with topical cooling. Aortic St. Jude Medical prostheses were inserted with the pivot perpendicular to the interventricular septum whereas most mitral valves were placed in the anatomic position, with use of a semiinterrupted running suture technique with Prolene 2-0 polypropylene sutures. Preservation of posterior mitral leaflet was not realized at the time these operations were done. Combined coronary artery bypass grafting with saphenous vein was done in 44 cases $(14 \%)$. Additional procedures and diameters of St. Jude Medical valves used are shown in Table IV.

Anticoagulation. Intravenous heparin anticoagulation therapy was started on the first postoperative day and continued until the prothrombin time (PT) could be regulated by daily warfarin administration. The recommended anticoagulation level was a PT of $15 \%$ to $25 \%$ (corresponding international normalized ratio [INR], 3 to 4.5). After hospital discharge, the referring physician was in charge of the anticoagulation control.

Follow-up. One-time follow-up data were obtained by questionnaires addressed to the physicians in charge of the patients (response rate $93 \%$ ) and by telephone inter-
Table II. Characteristics of pathologic valves

\begin{tabular}{lccc}
$(n=354)$ & & & \\
\hline & $\begin{array}{c}\text { Aortic } \\
(n=226)\end{array}$ & $\begin{array}{c}\text { Mitral } \\
(n=126)\end{array}$ & $\begin{array}{c}\text { Tricuspid } \\
(n=2)\end{array}$ \\
\hline Dysfunction & & & \\
$\quad$ Stenosis & $55(24.4 \%)$ & $20(15.9 \%)$ & 2 \\
$\quad$ Regurgitation & $76(33.6 \%)$ & $55(43.7 \%)$ & \\
$\quad$ Mixed & $95(42.0 \%)$ & $51(40.4 \%)$ & \\
Etiology & & & \\
$\quad$ Rheumatic & $53(23.5 \%)$ & $48(38.0 \%)$ & 2 \\
Congenital & $97(42.9 \%)$ & - & \\
Myxomatous & $12(5.3 \%)$ & $48(38.0 \%)$ & \\
Endocarditic & $26(11.5 \%)$ & $18(14.3 \%)$ & \\
Degenerative (calcific) & $17(7.5 \%)$ & $1(0.8 \%)$ & \\
Prosthetic dysfunction & $6(2.7 \%)$ & $2(1.6 \%)$ & \\
Ischemic & - & $3(2.4 \%)$ & \\
Other causes & $10(4.4 \%)$ & $1(0.8 \%)$ & \\
Unknown & $5(2.2 \%)$ & $5(4.0 \%)$ & \\
\hline
\end{tabular}

view with all living patients or the patient's family in case of death; further information about complications was obtained from hospital reports. Death certificates were reviewed for each case of sudden death or death from unknown cause. Fourteen patients were lost to follow-up; follow-up was thus $96 \%$ complete and represented 2967 patient-years with a mean of 9.5 years per patient, a median of 10.8 years, and a maximum of 15.6 years.

Definitions. We used the guidelines of The Society of Thoracic Surgeons and The American Association for Thoracic Surgery ${ }^{21}$ for the definitions of morbid events and mortality and the recommendations of Bodnar and 
Table III. Hemodynamic and angiographic preoperative data (for single valvulopathy only)

\begin{tabular}{|c|c|c|c|c|c|c|c|c|}
\hline & $\begin{array}{l}\text { Cardiac index } \\
\left(\mathrm{L} / \mathrm{min} / \mathrm{m}^{2}\right)\end{array}$ & $\begin{array}{l}E F \\
(\%)\end{array}$ & $\begin{array}{c}M P A P \\
(m m H g)\end{array}$ & $\begin{array}{c}P W P \\
(m m H g)\end{array}$ & $\begin{array}{l}\text { LVEDI } \\
\left(\mathrm{ml} / \mathrm{m}^{2}\right)\end{array}$ & $\begin{array}{l}\text { LVESI } \\
\left(\mathrm{ml} / \mathrm{m}^{2}\right)\end{array}$ & $\begin{array}{l}\text { Valve surface } \\
\qquad\left(\mathrm{cm}^{2}\right)\end{array}$ & $\begin{array}{c}\text { Maximum } \\
\text { gradient } \\
\text { (mm Hg) }\end{array}$ \\
\hline \multicolumn{9}{|l|}{ Aortic pathology } \\
\hline Stenosis $(n=50)$ & $2.69 \pm 0.71$ & $68 \pm 18$ & $23 \pm 9$ & $15 \pm 7$ & $93 \pm 46$ & $37 \pm 18$ & $0.58 \pm 0.22$ & $75 \pm 28$ \\
\hline Regurgitation $(n=56)$ & $2.69 \pm 0.69$ & $59 \pm 15$ & $22 \pm 8$ & $15 \pm 7$ & $158 \pm 50$ & $69 \pm 40$ & & \\
\hline $\begin{array}{l}\text { Mixed stenosis and regurgi- } \\
\text { tation }(n=88)\end{array}$ & $2.58 \pm 0.76$ & $65 \pm 14$ & $26 \pm 14$ & $18 \pm 10$ & $108 \pm 39$ & $41 \pm 29$ & $0.73 \pm 0.40$ & $69 \pm 31$ \\
\hline \multicolumn{9}{|l|}{ Mitral pathology } \\
\hline Stenosis $(n=14)$ & $2.22 \pm 0.52$ & $73 \pm 10$ & $30 \pm 9$ & $23 \pm 6$ & $89 \pm 18$ & $26 \pm 8$ & $0.88 \pm 0.26$ & $15 \pm 5$ \\
\hline Regurgitation $(n=49)$ & $2.22 \pm 0.54$ & $64 \pm 14$ & $30 \pm 12$ & $21 \pm 9$ & $139 \pm 50$ & $53 \pm 34$ & & \\
\hline $\begin{array}{l}\text { Mixed stenosis and regurgi- } \\
\text { tation }(n=31)\end{array}$ & $2.08 \pm 0.38$ & $66 \pm 11$ & $32 \pm 14$ & $23 \pm 8$ & $92 \pm 28$ & $33 \pm 18$ & $1.28 \pm 0.60$ & $15 \pm 5$ \\
\hline
\end{tabular}

Results are indicated as mean plus or minus standard deviation. $E F$, Ejection fraction; $M P A P$, mean pulmonary arterial pressure; $P W P$, pulmonary wedge pressure; $L V E D I$, left ventricular end-diastolic index; $L V E S I$, left ventricular end-systolic index.

Table IV. Surgical procedures

\begin{tabular}{lrr}
\hline & Valve size $(\mathrm{mm})$ & No. \\
\hline Valve position & 19 & \\
Aortic & 21 & 12 \\
& 23 & 44 \\
& 25 & 58 \\
& 27 & 62 \\
& 29 & 36 \\
Mitral & 31 & 12 \\
& 27 & 3 \\
& 29 & 15 \\
Tricuspid & 31 & 94 \\
& 33 & 14 \\
Additional operative procedures & 23 & 1 \\
Coronary artery bypass grafting & 31 & 1 \\
Aortic root replacement & & \\
Tricuspid annuloplasty & & 44 \\
Other & & 3 \\
\end{tabular}

colleagues $^{22}$ to report thrombosis, embolism, and bleeding. We present the incidence of emboli according to the criteria of McGoon. ${ }^{23}$ Some review of the precise terms used is helpful: hemorrhages referred to any episodes that necessitated hospital care (inpatient or outpatient care) for diagnostic or therapeutic interventions and to episodes that led to death. Ischemic cerebrovascular accidents were classified as follows: (1) transient ischemic attack: focal neurologic signs of vascular origin lasting less than 24 hours; (2) reversible neurologic deficit: neurologic deficit lasting more than 24 hours but resolving before hospital discharge; (3) major stroke: neurologic defects still present at hospital discharge; and (4) fatal stroke. Valverelated hemolytic anemia was defined as the presence of normocytic normochromic anemia (hemoglobin value $<13 \mathrm{gm} / 100 \mathrm{ml}$ for men, $<12 \mathrm{gm} / 100 \mathrm{ml}$ for women) with a lactate dehydrogenase elevation and/or a haptoglobin decrease and/or schistocytes, in the absence of any other known cause. Sudden death was defined as a nonaccidental, witnessed or unwitnessed death of a person for whom time and mode of death were unexpected. Anticoagulation at the time of events was considered to be efficient when the PT was between $15 \%$ and $30 \%$ and inefficient when the PT was greater than $30 \%$; overanticoagulation was defined by a PT less than $15 \%$. INR values were usually not used at the time under study.

Statistical analysis. Fisher's exact test and $\chi^{2}$ test were done to detect the univariate risk factors for early death. The different late valve-related events were expressed in linearized form (percent per patient-year) for which all events were considered. Actuarial survival and event-free curves were calculated with the Kaplan-Meier method. To establish the composite event-free and survival curves, valve-related deaths were given precedence over nonfatal complications when both occurred. Univariate comparisons of subgroups were made with the log-rank test. The list of the screened variables is given in the appendix. Cox's proportional-hazards models were then used to identify independent prognostic factors. We introduced into the models variables having a value of $p<0.1$ by log-rank test. When some covariates were highly correlated, we included the most significant one. Results of the multivariate analysis are given with estimates of the $\beta$ coefficient and as odds ratio (95\% confidence interval), with the significance level $p$ value for each variable.

\section{Results}

In-hospital ( $<30$ days) mortality and complications. In total, there were 54 in-hospital events in 50 patients (15.6\% of patients): 10 deaths (3.1\% of all patients; $2.6 \%$ with aortic valve replacement [AVR], $4.2 \%$ with mitral valve replacement [MVR], 3.1\% with multiple valve replacement [multiple VR]) and 44 nonfatal events. Fifteen patients $(4.7 \%)$ died or had long-term impairment after the operative period. Causes of in-hospital deaths and nonfatal events are shown in Table $\mathrm{V}$. The following risk factors for early death were found by univariate 
analysis: emergency operation $(p<0.001)$, New York Heart Association (NYHA) class IV symptoms $(p=0.002)$, additional procedures without coronary artery bypass grafting $(p=0.007)$, additional procedures including coronary artery bypass grafting ( $p=0.016)$, concomitant tricuspid anomaly $(p=0.025)$, acute endocarditis $(p=0.041)$, and cardiac index less than $2.5 \mathrm{~L} / \mathrm{m}^{2}(p=0.044)$.

\section{Late valve-related events}

Systemic embolism. Forty-six patients had $69 \mathrm{em}-$ bolic events ( 59 cerebral and 10 peripheral) at a linearized rate of 2.3\%/pt-yr (AVR, 2.0\%; MVR, $2.9 \%$; multiple VR, 2.0\%). With three fatal emboli the mortality rate was $4 \%$ (linearized rate of fatal emboli: $0.1 \% / \mathrm{pt}-\mathrm{yr}$ ). Fourteen patients had more than one embolism, which resulted in a high recurrence rate of $30 \%$. The actuarial probability of freedom from embolic events at 5, 10, and 13 years for AVR, MVR, and multiple VR is shown in Fig. 1. There were no differences among the three groups $(p=0.699)$. Anticoagulation level was known in 47 events and was insufficient in 32 (PT $31 \%$ to $40 \%, 2$; PT $41 \%$ to $50 \%, 5$; PT $51 \%$ to $60 \%$, 7 ; PT $>60 \%$, 18 ) and in the target range in 15 . Independent risk factors for embolism were cardiac failure and a history of prior systemic emboli (Table VI). Atrial fibrillation was not a significant risk factor in our series.

Anticoagulation-related hemorrhage. Ninety-nine events of anticoagulation-related hemorrhage occurred in 76 patients ( 18 cerebral and 81 peripheral) at a linearized rate of 3.3\%/pt-yr (AVR, 3.6\%; MVR, 3.4\%; multiple VR, 1.7\%). Twelve events were fatal (mortality rate $12 \%$; linearized rate of fatal hemorrhage, 0.4\%/pt-yr). Recurrent events occurred in 17 patients (recurrence rate $22 \%$ ). Intracranial hemorrhages are detailed in the next section. The gastrointestinal and genitourinary tracts were the most common locations of peripheral bleeding (respectively, $39 \%$ and $17 \%$ ). Only two patients with peripheral hemorrhage had permanent impairment. Overanticoagulation was present in only 30 of 56 events (PT $\leq 10 \%, 20$; PT $11 \%$ to $14 \%$, 10). Anticoagulation was in the target range in 18 and insufficient in 8. Actuarial freedom from hemorrhage at 5, 10, and 13 years is shown in Fig. 2. Freedom from hemorrhage tended to be smaller for the AVR group after 96 months, although the difference was not significant for the complete duration of follow-up $(p=0.365)$. Univariate analysis did not show any risk factor for hemorrhages among those listed in the appendix.
Table V. In-hospital events

\begin{tabular}{lc}
\hline & No. \\
\hline Deaths & \\
Valve-related & 1 \\
$\quad$ Prosthesis disinsertion & 7 \\
Cardiac & 1 \\
Noncardiac & 1 \\
Unknown & 10 \\
Total & $3.1 \%$ \\
Percent of patients & \\
Nonfatal events & \\
Valve-related & 3 \\
Cerebral embolism & 2 \\
Systemic embolism & 3 \\
Anticoagulation-related hemorrhage & 2 \\
Paravalvular leak & 2 \\
Hemolytic anemia & 17 \\
Cardiac & 15 \\
Surgical & $\frac{}{44}$ \\
Total & \\
Reoperation & 1 \\
Paravalvular leak repair & 6 \\
Hemostasis & 7 \\
Total & \\
\hline
\end{tabular}

Cerebrovascular accidents. There were 77 cerebrovascular accidents in 54 patients, at a linearized rate of $2.6 \% / \mathrm{pt}$-yr (AVR, 2.4\%; MVR, 3.1\%; multiple VR, $2.0 \%$ ). Ischemic accidents represented 59 events in 42 patients and were recurrent in 12 (recurrence rate $29 \%$ ). Of the ischemic cerebrovascular accidents $44 \%(N=26)$ were transient events most often diagnosed on a clinical basis; $12 \%(N=$ 7) were reversible neurologic deficits diagnosed either by computed tomographic scan (in 5) or clinically (in 2); $39 \%(N=23)$ were major strokes, and $5 \%(N=3)$ were fatal. Diagnosis was made by computed tomographic scan in all but three cases of major or fatal strokes.

Intracranial hemorrhages were less frequent with 18 events in 14 patients; however, their prognosis was more severe with 9 deaths (mortality, 50\%) because of intracerebral bleeding. Permanent impairment occurred in 1 case. Seven of the 18 events had been associated with recent head trauma. Diagnosis was made by computed tomographic scan in 14 cases, by lumbar puncture in 1, and clinically in 3 . Overanticoagulation was documented in 5 of 10 events. Independent risk factors for all cerebrovascular accidents were history of systemic emboli, age, and cardiac failure (Table VI). When univariate 


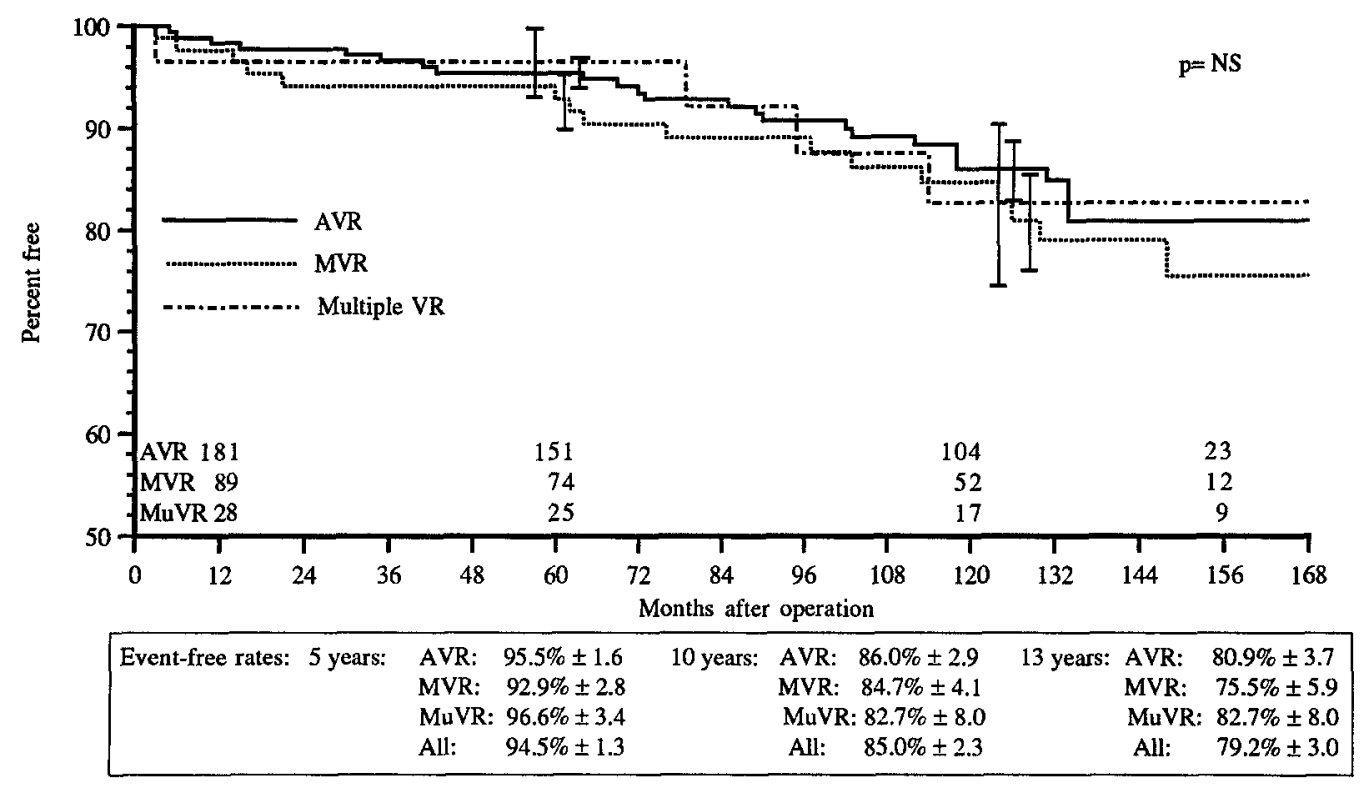

Fig. 1. Actuarial freedom from embolism after AVR, MVR, and multiple VR (MuVR) with standard error indicated at 60 and 120 months. Numbers above the time axis indicate the patients at risk at $1,5,10$, and 13 years. Differences between groups were not significant.

Table VI. Risk factors for late valve-related events*

\begin{tabular}{|c|c|c|c|c|c|c|c|}
\hline \multirow[b]{2}{*}{ Events } & \multicolumn{2}{|c|}{$\begin{array}{c}\text { Results of univariate analysis } \\
\text { by log-rank test }\end{array}$} & \multicolumn{5}{|c|}{$\begin{array}{l}\text { Cox's proportional hazards model } \\
\text { (independent risk factors) }\end{array}$} \\
\hline & Variables & $p$ Value & Variables & $\beta$ & $O R$ & $95 \% \mathrm{CI}$ & $p$ Value \\
\hline \multirow[t]{3}{*}{ Embolism } & Cardiac failure (CF) & 0.024 & $\mathrm{CF}$ & 1.197 & 3.3 & $1.3,8.5$ & 0.013 \\
\hline & $\begin{array}{l}\text { History of prior systemic em- } \\
\text { bolism (HSE) }\end{array}$ & 0.046 & HSE & 1.065 & 2.9 & $1.2,7.0$ & 0.018 \\
\hline & $\begin{array}{l}\text { Postoperative atrial fibrilla- } \\
\text { tion }\end{array}$ & 0.075 & & & & & \\
\hline \multirow{4}{*}{$\begin{array}{l}\text { Cerebrovascular } \\
\text { accidents }\end{array}$} & Age $\geq 60$ years $(\mathrm{AGE})$ & 0.019 & HSE & 0.998 & 2.7 & $1.2,6.1$ & 0.015 \\
\hline & $\begin{array}{l}\text { History of prior systemic em- } \\
\text { bolism (HSE) }\end{array}$ & 0.034 & AGE & 0.666 & 1.9 & $1.1,3.4$ & 0.018 \\
\hline & Cardiac failure (CF) & 0.063 & $\mathrm{CF}$ & 0.714 & 2.0 & $1.0,4.1$ & 0.043 \\
\hline & Prosthetic diameter $\leq 23 \mathrm{~mm}$ & 0.082 & & & & & \\
\hline \multirow[t]{5}{*}{ Endocarditis } & Diabetes (Diab) & 0.001 & Diab & 2.338 & 10 & $2.8,39$ & $<0.001$ \\
\hline & Degenerative cause & 0.016 & $\mathrm{OH}$ & 1.991 & 7.3 & $1.4,39$ & 0.019 \\
\hline & Alcoholism $(\mathrm{OH})$ & 0.026 & AVR & 2.333 & 10 & $1.1,93$ & 0.038 \\
\hline & Aortic stenosis & 0.035 & & & & & \\
\hline & AVR & 0.045 & & & & & \\
\hline
\end{tabular}

$O R$, Odds ratio; $C I$, confidence interval.

${ }^{*}$ Univariate and multivariate analysis. Variables identified by $\log$-rank test with a $p<0.1$ were taken for the multivariate analysis.

analysis was done on the group with intracranial hemorrhages only, no risk factor could be identified. Actuarial freedom from cerebrovascular accident and intracranial hemorrhage and for the following five valve-related complications individually and all valve-related events is described in Table VII.
Prosthesis thrombosis. Four cases of valve thrombosis occurred during the follow-up (linearized rate $0.1 \% / \mathrm{pt}-\mathrm{yr})$. There were two cases of partial thrombosis successfully treated by prosthesis replacement, one case of complete obstructive fatal thrombosis, and one case manifested by a fatal cerebral embo- 


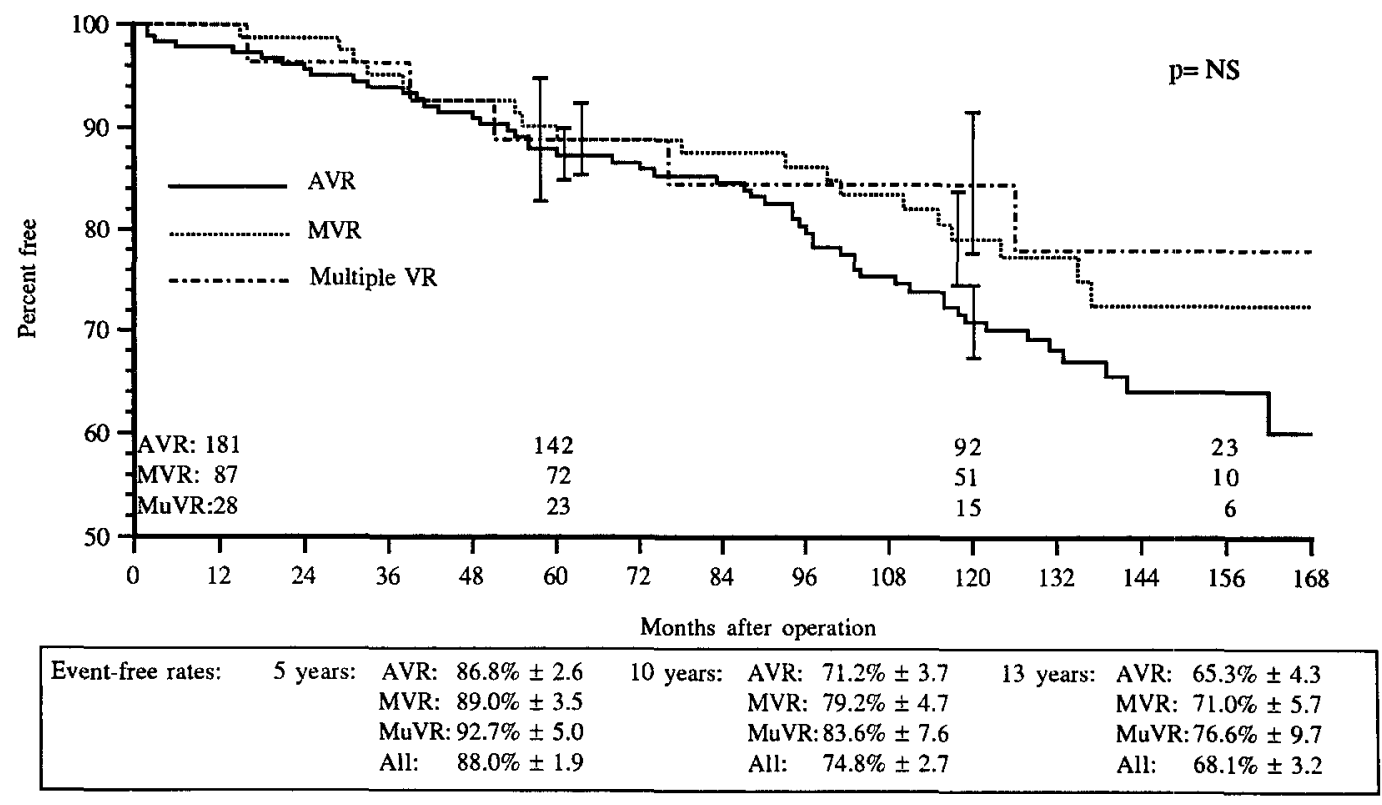

Fig. 2. Actuarial freedom from anticoagulation-related hemorrhage after AVR, MVR, and multiple VR ( $M u V R$ ) with standard error indicated at 60 and 120 months. Numbers above the time axis indicate the patients at risk at $1,5,10$, and 13 years. Differences between groups were not significant.

lism. Three events occurred after AVR (diameter, 21, 23, and $27 \mathrm{~mm}$ ) and one after AVR with MVR (21 and $31 \mathrm{~mm}$, respectively) in which both valves were thrombosed. Insufficient anticoagulation was documented at the time of the event and several times before in three patients. Anticoagulation was adequate on admission to the hospital in the fourth but had probably been previously intermittently low because two transient ischemic attacks occurred in the weeks before the fatal event.

Endocarditis. Ten patients had 11 events of endocarditis (recurrence rate, 10\%); 10 events occurred in the AVR group and 1 in the MVR group (linearized rate: overall, $0.4 \% / \mathrm{pt}-\mathrm{yr}$; AVR, $0.6 \% / \mathrm{pt}-$ yr; MVR 0.1\%/pt-yr). Two cases were fatal (mortality rate, $18 \%$ ). No survivors needed reoperation. Independent risk factors for endocarditis were diabetes mellitus, alcoholism, and AVR (Table VI).

Prosthesis dysfunction. No case of structural dysfunction was observed. Paravalvular leak was diagnosed 11 times in 9 patients and led to reoperation 7 times (recurrence rate, 11\%). One case of aortic subvalvular stenosis because of fibrosis and muscular hypertrophy and one case of incomplete closure of an aortic prosthesis because of pannus entrapment also necessitated reoperation. Eleven aortic prostheses and two mitral prostheses were involved (linearized rates: for all dysfunctions, $0.4 \% / \mathrm{pt}-\mathrm{yr}$;
AVR, $0.6 \% / \mathrm{pt}-\mathrm{yr}$; MVR $0.2 \% / \mathrm{pt}-\mathrm{yr}$ ). The only risk factor identified univariately was age 45 years or younger $(p=0.030)$.

Hemolytic anemia. Four cases of hemolytic anemia (linearized rate, $0.1 \% / \mathrm{pt}-\mathrm{yr}$ ) were diagnosed. Three of them were a result of moderate or severe paravalvular leak in the aortic position and the condition normalized after reoperation. In the fourth case a significant leak was not found; the anemia was managed by medical treatment.

Reoperation. Eleven reoperations were done in nine cases (linearized rate: overall, $0.4 \% / \mathrm{pt}-\mathrm{yr}$, AVR, $0.5 \% /$ pt-yr; MVR, 0.2\%/pt-yr). Paravalvular leaks necessitated prosthesis replacement in three cases and simple closure of the leak in four. Two cases of valve dysfunction and two of valve thrombosis necessitated valve replacement. No significant risk factor could be identified.

Overall valve-related complications. Including all fatal and nonfatal emboli, anticoagulation-related hemorrhages, prosthetic dysfunctions, hemolytic anemias, endocarditis, valve thrombosis, and reoperations, valve-related complications occurred at a linearized rate of $7.0 \% / \mathrm{pt}$-yr for the whole group (AVR, 7.6\%; MVR, 6.9\%; multiple VR, 4.4\%). The overall mortality rate for these complications was 9\%. Actuarial estimates are given in Table VII. There was no statistical difference between opera- 
Table VII. Actuarial freedom from various valve-related complications at 5, 10, and 13 years

\begin{tabular}{|c|c|c|c|c|}
\hline \multirow[b]{2}{*}{ Event } & \multirow[b]{2}{*}{ Operation } & \multicolumn{3}{|c|}{ Percent freedom } \\
\hline & & $5 y r$ & $10 y r$ & $13 y r$ \\
\hline \multirow[t]{4}{*}{ Cerebrovascular accident } & AVR & $93.6 \pm 1.9$ & $81.5 \pm 3.2$ & $75.1 \pm 4.1$ \\
\hline & MVR & $92.8 \pm 2.8$ & $83.1 \pm 4.3$ & $77.6 \pm 5.1$ \\
\hline & MuVR & $96.6 \pm 3.4$ & $82.7 \pm 8.0$ & $82.7 \pm 8.0$ \\
\hline & All & $93.4 \pm 1.5$ & $81.8 \pm 2.5$ & $76.5 \pm 3.0$ \\
\hline \multirow[t]{4}{*}{ Intracranial hemorrhage } & AVR & $97.6 \pm 1.2$ & $93.9 \pm 2.0$ & $92.3 \pm 2.5$ \\
\hline & MVR & $97.6 \pm 1.7$ & $94.8 \pm 2.5$ & $94.8 \pm 2.5$ \\
\hline & MuVR & 100 & 100 & 100 \\
\hline & All & $97.8 \pm 0.9$ & $94.8 \pm 1.4$ & $93.9 \pm 1.7$ \\
\hline Prosthesis thrombosis & All & $98.9 \pm 0.6$ & $98.5 \pm 0.7$ & $98.5 \pm 0.7$ \\
\hline \multirow[t]{4}{*}{ Endocarditis } & AVR & $99.4 \pm 0.6$ & $95.8 \pm 1.7$ & $91.8 \pm 2.9$ \\
\hline & MVR & $98.8 \pm 1.2$ & $98.8 \pm 1.2$ & $98.8 \pm 1.2$ \\
\hline & MuVR & 100 & 100 & 100 \\
\hline & All & $99.3 \pm 0.5$ & $97.2 \pm 1.1$ & $94.9 \pm 1.7$ \\
\hline \multirow[t]{4}{*}{ Nonstructural prosthesis dysfunction } & AVR & $97.8 \pm 1.1$ & $96.4 \pm 1.5$ & $92.2 \pm 3.0$ \\
\hline & MVR & $98.9 \pm 1.1$ & $97.5 \pm 1.8$ & $97.5 \pm 1.8$ \\
\hline & MuVR & 100 & 100 & 100 \\
\hline & All & $98.3 \pm 0.7$ & $97.1 \pm 1.0$ & $94.6 \pm 1.8$ \\
\hline Hemolytic anemia & All & $99.3 \pm 0.5$ & $98.5 \pm 0.7$ & $98.5 \pm 0.7$ \\
\hline \multirow[t]{4}{*}{ Reoperation } & AVR & $98.4 \pm 0.9$ & $97.0 \pm 1.3$ & $93.6 \pm 2.9$ \\
\hline & MVR & $98.9 \pm 1.1$ & $97.5 \pm 1.8$ & $97.5 \pm 1.8$ \\
\hline & MuVR & 100 & 100 & 100 \\
\hline & All & $98.7 \pm 0.7$ & $97.4 \pm 1.0$ & $95.5 \pm 1.7$ \\
\hline \multirow[t]{4}{*}{ All valve-related events } & AVR & $86.5 \pm 2.6$ & $62.8 \pm 3.9$ & $47.4 \pm 4.9$ \\
\hline & MVR & $86.0 \pm 3.7$ & $71.2 \pm 5.1$ & $56.0 \pm 6.3$ \\
\hline & MuVR & $89.4 \pm 5.8$ & $76.5 \pm 8.5$ & $57.7 \pm 10.4$ \\
\hline & All & $86.3 \pm 2.0$ & $66.3 \pm 3.0$ & $50.9 \pm 3.6$ \\
\hline
\end{tabular}

MuVR, Multiple VR.

tive groups when the entire follow-up was considered $(p=0.502)$, but beyond 8 years we observed a trend toward more complications in the AVR group.

Late deaths, overall deaths, and survival. There were 125 late deaths during the follow-up at a linearized rate of $4.2 \% / \mathrm{pt}$-yr (AVR, 4.7\%; MVR, 3.1\%; multiple VR, $4.1 \%$ ). The causes of late death are reported in Table VIII. For univariate and multivariate analysis we considered early and late deaths together (overall mortality), or a total of 135 deaths. Actuarial survival curves for AVR, MVR, and multiple VR are shown in Fig. 3. Predictors of mortality identified by univariate and multivariate analysis are shown in Table IX. Despite the good correlation between mortality and extent of coronary artery disease (Fig. 4), this was not an independent risk factor when age and cardiac failure were considered. Because cardiac index, cardiothoracic index, and ejection fraction were measured only in subsets of patients, using these factors together in the multivariate analysis was not possible and a separate Cox's model was defined for each of them. Thus independence among these three covariates was not tested (the same applied to the multivariate analysis for sudden death, valve-related death, and cardiac non-valve-related death). Table IX only presents the independent risk factors for the model including ejection fraction. A high cardiothoracic index and a low cardiac index were independent risk factors for overall mortality in their respective models. Survival in the AVR group tended to be worse than that in the MVR group, although this difference did not reach significance $(p=0.069)$. When the analysis was done separately for the AVR group, the same risk factors for mortality were identified univariately. For the MVR group, the risk factors identified by log-rank test were coronary artery bypass grafting, age 60 years or older, cardiothoracic index, emergency operation, NYHA class III or IV, alcoholism, diabetes, and presence of cardiovascular risk factors. Cardiac index was borderline $(p=$ 0.061 ). We did not find in either group a difference in survival between stenotic, regurgitant, or mixed lesions.

Sudden death, valve-related, and cardiac nonvalve-related mortality. Sudden death represented an important cause of late deaths $(24 / 125,19 \%)$ in 
our series $(19 \%, 18 \%, 25 \%$ of late deaths after AVR, MVR, multiple VR, respectively; $p=0.565$ ). There were 14 men and 10 women with a mean age of 62 years who died after a mean of 5.2 years. Nine of these patients had coronary disease, 2 had been treated for malignant ventricular arrythmias, and 2 had both diseases. Half of these patients had left ventricular hypertrophy and $29 \%$ underwent coronary artery bypass grafting at the time of the valve replacement. Comparing the variables listed in the appendix between the sudden death group and the valve-related death group without sudden death, we found that the sudden death group was characterized by a higher mean end-diastolic index $(p=0.02)$ and a higher proportion of patients with ejection fraction less than $50 \%(p=0.016)$ whereas a higher proportion of small prostheses $(\leq 23 \mathrm{~mm}$ ) was found in the valve-related death group. Comparing the sudden death group with the group of cardiac non-valve-related deaths, we noted only a greater frequency of preoperative aortic stenosis in the sudden death group $(p=0.04)$. The risk factors for sudden death and cardiac non-valve-related death were similar (Table IX). High cardiothoracic index and low cardiac index were independent factors for cardiac non-valve-related death in their models, and the latter was also a risk factor for sudden death. In comparison, the prognostic factors for the valverelated death group were different (Table IX). Actuarial freedom from valve-related deaths, with and without sudden deaths included, is shown in Fig. 5. Actuarial freedom rates for sudden death only at 5 years were $96.6 \% \pm 1.1 \%$, at 10 years $91.5 \% \pm$ $1.8 \%$, and at 13 years $91.0 \% \pm 1.8 \%$. Actuarial freedom rates for cardiac non-valve-related death only at 5 years were $95.4 \% \pm 1.2 \%$, at 10 years $87.3 \% \pm 2.1 \%$, and at 13 years $81.4 \% \pm 2.8 \%$. At the end of follow-up, $10 \%$ of patients in preoperative NYHA class I, $35 \%$ in class II, $48 \%$ in class III, and 55\% in class IV had died after a mean survival time of $112,83,78$, and 56 months, respectively.

Valve-related morbidity and mortality. Fig. 6 shows the actuarial freedom from fatal and nonfatal valve-related complications and from valve-related mortality and permanent impairment. Two curves are given for each endpoint to take into account the inclusion or exclusion of sudden death as a valverelated complication. No differences existed among the three operative groups for these endpoints. Multivariate analysis for each of these combined events showed that when sudden death was in-
Table VIII. Causes of late mortality (125/311 patients, $40.2 \%$ )

\begin{tabular}{lcc} 
Cause of late death & $\begin{array}{c}\text { No. of } \\
\text { patients }\end{array}$ & $\begin{array}{c}\text { Percent of } \\
\text { late deaths }\end{array}$ \\
\hline Valve-related & 19 & 15 \\
Cerebral embolism & 3 & \\
Intracranial hemorrhage & 9 & \\
Gastrointestinal tract hemorrhage & 2 & \\
Intrathoracic hemorrhage & 1 & \\
Endocarditis & 2 & \\
Valve thrombosis & 2 & \\
Sudden death & 24 & 19 \\
Cardiac non-valve-related & 39 & 31 \\
Cardiac failure & 32 & \\
Arrhythmia & 4 & \\
Heart graft rejection & 1 & \\
Infarction & 2 & \\
Noncardiac & 36 & 29 \\
Cancer & 19 & \\
Infection & 8 & \\
Other* & 9 & \\
Unknown & 7 & 6 \\
\hline
\end{tabular}

*Other: 2 ruptured aortic aneurysms, 2 pulmonary emboli, 1 perforated gastric ulcer, 1 acute arterial failure in a patient with severe obstructive atherosclerosis in both legs, 1 suicide, 1 renal failure, 1 amyotrophic lateral scierosis.

cluded, the rate of complications was influenced by cardiac failure and coronary artery disease.

Functional improvement. Ninety percent of the survivors were in NYHA class I or II after a mean follow-up of 9.5 years in comparison with $43 \%$ before the valve replacement. The percentage of survivors in NYHA class I or II at the end of follow-up was $93 \%, 90 \%$, and $83 \%$ for patients in preoperative classes I or II, III, and IV, respectively. At the end of follow-up 80 patients were not retired. The degree of activity was known for 65 of the patients: $40(62 \%)$ were working full-time, $10(15 \%)$ were partially active, and $15(23 \%)$ were not working and received complete disability compensation. The reason for complete or partial disability was valve-related in 5 cases, cardiac-related in 11, and noncardiac in 9 .

\section{Discussion}

The focus of our comments in this discussion will be on particular points concerning late complications.

Embolism. The linearized and actuarial eventfree rates for embolism are in accordance with the findings of recent studies confirming the low thrombogenicity of this valve. Table $\mathrm{X}$ presents the range of incidence of the usual valve-related end points 


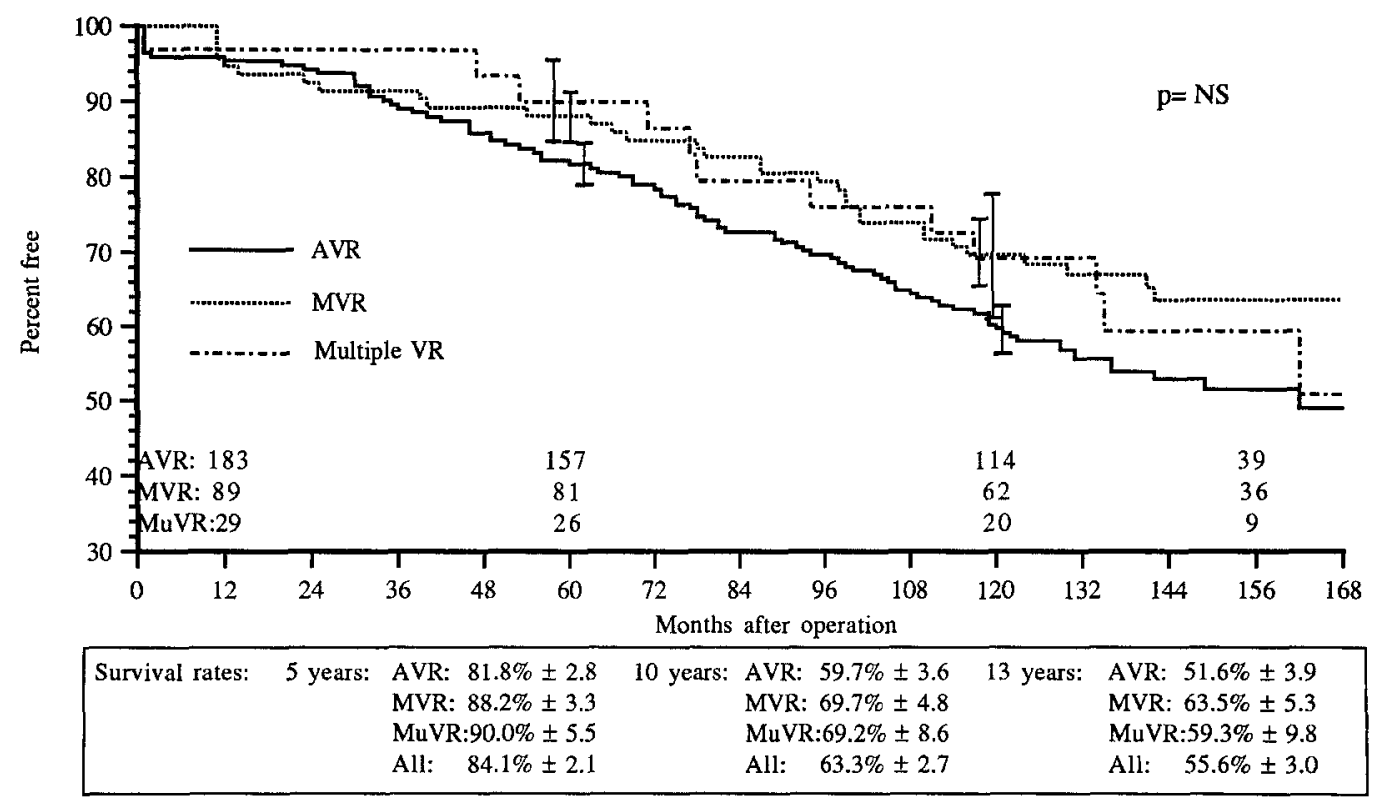

Fig. 3. Actuarial overall survival after AVR, MVR, and multiple VR (MuVR) with standard error indicated at 60 and 120 months. Numbers above the time axis indicate the patients at risk at 1,5,10, and 13 years. Differences between groups were not significant.

(expressed in linearized form) in 11 of the most important follow-up studies on the St. Jude Medical valve.* Our data show that embolism is neither the most frequent nor the most dangerous valve-related complication in terms of survival. However, it is the most recurrent event. Most emboli are related to inadequate anticoagulation. This emphasizes the need for adequate anticoagulation after valve replacement with the St. Jude Medical prosthesis. Atrial fibrillation is not a significant incremental risk factor for embolism but is probably partially involved as shown in a later section of this discussion. As also demonstrated by others, ${ }^{24-26}$ a history of prior embolism is an independent risk factor for recurrent events. The reason is not evident, but we nevertheless found atrial fibrillation and cardiovascular risk factors to be more frequent in the group with a history of emboli. Cardiac failure as the indication for operation is an important risk factor because it represents patients with a greater cardiothoracic index, larger atrial diameter, higher NYHA class, and more mitral abnormalities. These findings, as emphasized by Horstkotte and associates, ${ }^{27}$ confirm the need to consider cardiac comorbidity in

*References $1,2,4,9,10,12-15,17$, and 18 . defining the best range for anticoagulation in individual patients.

Hemorrhage. Hemorrhage was the most frequent complication in our series but was without permanent consequences in $86 \%$ of the cases. The link to inadequate anticoagulation is far less evident for hemorrhage than for embolism. The rate of hemorrhages in the present report was higher than in most comparable studies. The disparity in reporting bleeding complications certainly accounts for this. Indeed there is a wide discrepancy in the published incidence of hemorrhages (and emboli) as shown in Table $X$, and this cannot be attributed only to variations in the anticoagulation target range or in the mode of control of anticoagulation. Because every bleeding episode that necessitated hospital care was counted (among which many cases were treated on an outpatient basis), we certainly included more benign events than most reports. Horstkotte and associates ${ }^{27}$ observed in a prospective study a linearized rate of $6.7 \% / \mathrm{pt}-\mathrm{yr}$ taking into account all benign and severe hemorrhagic events. This indicates that rates in retrospective studies are probably underestimated (the same conclusion applies to embolic events). It has been clear for the past few years that the anticoagulation target 
Table IX. Risk factors for overall mortality, sudden death, valve-related death, and cardiac non-valve-related death*

\begin{tabular}{|c|c|c|c|c|c|c|c|}
\hline \multirow[b]{2}{*}{ Event } & \multicolumn{2}{|l|}{$\begin{array}{c}\text { Results of univariate analysis } \\
\text { by log-rank test }\end{array}$} & \multicolumn{5}{|c|}{$\begin{array}{l}\text { Cox's proportional hazards model } \\
\text { (independent risk factors) }\end{array}$} \\
\hline & Variables & $p$ Value & Variables & $\beta$ & $O R$ & $95 \% \mathrm{CI}$ & $p$ Value \\
\hline \multirow[t]{17}{*}{ Overall mortality } & Age $\geq 60 \mathrm{yr}(\mathrm{AGE}) \dagger$ & $<0.001$ & AGE & 0.923 & 2.5 & $1.7,3.8$ & $<0.001$ \\
\hline & Presence of coronary diseaset & $<0.001$ & EF & 0.992 & 2.7 & $1.7,4.2$ & $<0.001$ \\
\hline & Severity of coronary disease & $<0.001$ & $\mathrm{OH}$ & 0.817 & 2.3 & $1.3,4.0$ & 0.006 \\
\hline & Cardiothoracic index $>0.50$ & $<0.001$ & HSE & 0.865 & 2.4 & $1.3,4.5$ & 0.008 \\
\hline & Ejection fraction $<50 \%(\mathrm{EF}) \dagger$ & $<0.001$ & & & & & \\
\hline & Cardiac index $<2.5 \mathrm{~L} / \mathrm{m}^{2}$ & $<0.001$ & & & & & \\
\hline & CABG & $<0.001$ & & & & & \\
\hline & Diabetes mellitus $\dagger$ & 0.001 & & & & & \\
\hline & Alcoholism $(\mathrm{OH}) \dagger$ & 0.002 & & & & & \\
\hline & NYHA III-IV versus I-II† & 0.002 & & & & & \\
\hline & Presence of $\mathrm{CV}$ risk factors & 0.012 & & & & & \\
\hline & Degenerative cause $\dagger$ & 0.018 & & & & & \\
\hline & Emergency operation $\dagger$ & 0.029 & & & & & \\
\hline & NYHA IV versus I-III & 0.039 & & & & & \\
\hline & History of systemic embolism (HSE) $\dagger$ & 0.049 & & & & & \\
\hline & MVR versus AVR + multiple VR & 0.074 & & & & & \\
\hline & Syncopett & 0.082 & & & & & \\
\hline \multirow[t]{9}{*}{ Sudden death } & Severity of coronary disease (SCOR) $\dagger$ & 0.001 & $\mathrm{EF}$ & 1.157 & 3.2 & $1.2,8.1$ & 0.016 \\
\hline & Ejection fraction $<50 \%(\mathrm{EF}) \dagger$ & 0.001 & SCOR & 0.457 & 1.6 & $1.1,2.3$ & 0.023 \\
\hline & Presence of CV risk factors & 0.011 & & & & & \\
\hline & $\mathrm{CABG} \dagger$ & 0.011 & & & & & \\
\hline & Angor as indication for operation $\dagger$ & 0.012 & & & & & \\
\hline & Presence of coronary disease & 0.015 & & & & & \\
\hline & Alcoholismt & 0.016 & & & & & \\
\hline & Age $\geq 60 \mathrm{yr}_{\uparrow}^{\dagger}$ & 0.042 & & & & & \\
\hline & Cardiac index $<2.5$ & 0.045 & & & & & \\
\hline \multirow[t]{6}{*}{ Valve-related death } & Prosthetic diameter $\leq 23 \mathrm{~mm}($ PDIA $) \dagger$ & 0.001 & $\mathrm{OH}$ & 1.540 & 4.7 & $1.3,17$ & 0.018 \\
\hline & Degenerative cause $(\mathrm{DC}) \dagger$ & 0.001 & $\mathrm{DC}$ & 1.385 & 4.0 & $1.2,13$ & 0.023 \\
\hline & Aortic stenosist & 0.021 & PDIA & 1.062 & 2.9 & $1.1,7.7$ & 0.033 \\
\hline & Diabetes mellitust & 0.041 & & & & & \\
\hline & Alcoholism $(\mathrm{OH}) \dagger$ & 0.047 & & & & & \\
\hline & Age $\geq 60 \mathrm{yr}^{\dagger}$ & 0.077 & & & & & \\
\hline \multirow{9}{*}{$\begin{array}{l}\text { Cardiac non-valve- } \\
\text { related death }\end{array}$} & Age $\geq 60 \mathrm{yr} t$ & 0.001 & HSE & 1.235 & 3.4 & $1.4,8.6$ & 0.005 \\
\hline & Presence of coronary disease $(\mathrm{COR}) \dagger$ & 0.001 & EF & 1.134 & 3.1 & $1.5,6.7$ & 0.007 \\
\hline & Ejection fraction $<50 \%(\mathrm{EF}) \dagger$ & 0.002 & COR & 0.830 & 2.3 & $1.1,4.9$ & 0.012 \\
\hline & $\mathrm{CABG}$ & 0.008 & & & & & \\
\hline & Cardiac index $<2.5$ & 0.010 & & & & & \\
\hline & Cardiothoracic index $>0.50$ & 0.015 & & & & & \\
\hline & Pulmonary wedge pressure $>20$ & 0.020 & & & & & \\
\hline & Emergency operation $\uparrow$ & 0.021 & & & & & \\
\hline & History of systemic embolism (HSE) $\uparrow$ & 0.049 & & & & & \\
\hline
\end{tabular}

$O R$, Odds ratio; $C I$, confidence interval; $C A B G$, coronary artery bypass grafting; $C V$, cardiovascular.

${ }^{*}$ Univariate and multivariate analysis.

Indicates variables entered in the Cox's models. Reasons for excluding variables are given in the paragraphs on statistics and on late deaths.

Findicates variables with a favorable influence on survival.

for the St. Jude Medical prosthesis should be lower than was previously advised to reduce hemorrhages without an increased risk of thromboemboli. ${ }^{18,27-28}$ The recently published guidelines of the European Society of Cardiology recommend an INR of 2.5 to 3.0 after AVR and 3.0 to 3.5 after MVR with the second-generation valves. ${ }^{29}$ In other respects, hemorrhages seem slightly more frequent in the AVR group beyond 9 years (Fig. 2); we do not have any satisfactory explanation for that. 


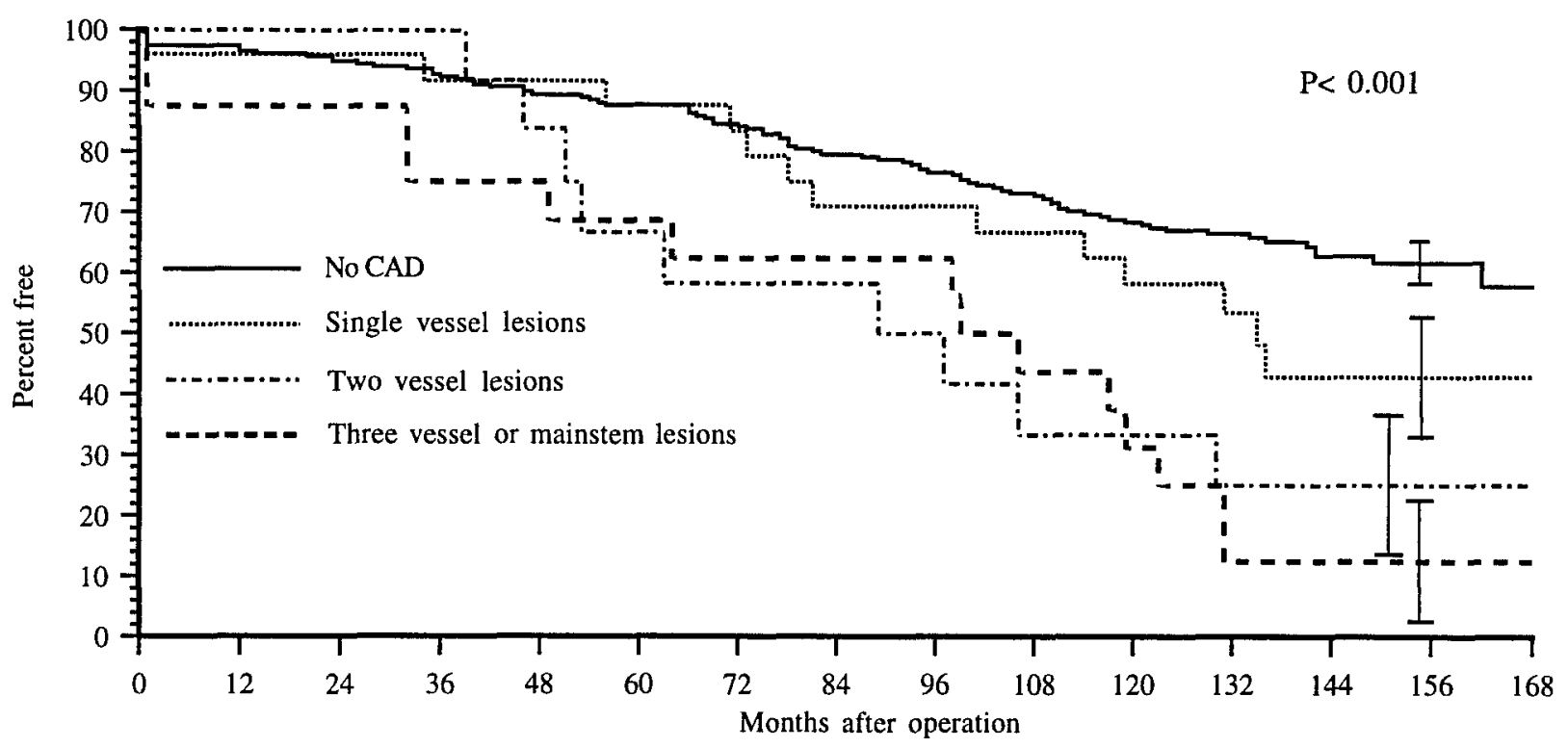

Fig. 4. Actuarial survival after valve replacement, stratified by the number of pathologic main coronary arteries. $C A D$, Coronary artery disease.

Cerebrovascular accidents. Eighty-six percent of all emboli and $18 \%$ of all hemorrhagic events were cerebral; the former were lethal in $5 \%$ and the latter in $50 \%$. Because of the predominance of ischemic cerebrovascular accidents, risk factors for cerebrovascular accidents are similar to those for embolism, but age plays a more significant part for cerebrovascular accidents.

Other valve-related complications. Our results happen to be within the ranges presented in Table $\mathrm{X}$. Valve thrombosis is a threatening complication with a $50 \%$ mortality rate and is strongly linked to deficient anticoagulation. Endocarditis is significantly more frequent in patients with diabetes or alcoholism or when the underlying valve disease was aortic stenosis, particularly that of a degenerative cause. Alcoholism, diabetes, and AVR are independent factors. If degenerative disease is a well-known risk factor of native valve endocarditis, especially in the elderly, to our knowledge it has not been described as a persistent risk factor after valve replacement. This may be because of the persistence or the relapse of calcific depositions and areas of epithelial denudation, which promote the development of vegetations. Furthermore, patients in this group are older and age is a major risk factor for all events. Multiple VR was not associated with an increased risk of endocarditis in the present report but this remains controversial in the literature.
Overall mortality and survival. The linearized rates of mortality and actuarial survival at 10 years are comparable with those given by Ibrahim, ${ }^{17}$ Khan, ${ }^{13}$ and Fernandez ${ }^{12}$ and their coworkers. Baudet and associates ${ }^{18}$ showed higher survival rates in a comparable sample of patients, but freedom from valve-related death was the same. Horstkotte and associates ${ }^{27}$ also observed a significantly better overall survival at 10 years (AVR, 85\%; MVR, 78\%; double VR, 72\%). However, the population was different with more female patients, younger patients, and a prospective follow-up that could help identify complications earlier and contribute to a better prognosis. With respect to risk factors for global mortality, coronary artery disease was not independent when considered with age and cardiac failure. Cardiothoracic index and ejection fraction are simple and useful parameters to determine the best time for operation and to predict the outcome for the patient. Syncope, as an indication for operation, has a favorable effect on late survival; this has already been described in previous series of aortic stenosis. History of prior systemic emboli was an independent risk factor for overall mortality and cardiac death; it was not related to an increased incidence of fatal cerebral emboli as might be expected and, indeed, the first cause of death in this subgroup was cardiac failure with no valve-related death. Patients with a history of prior emboli show 


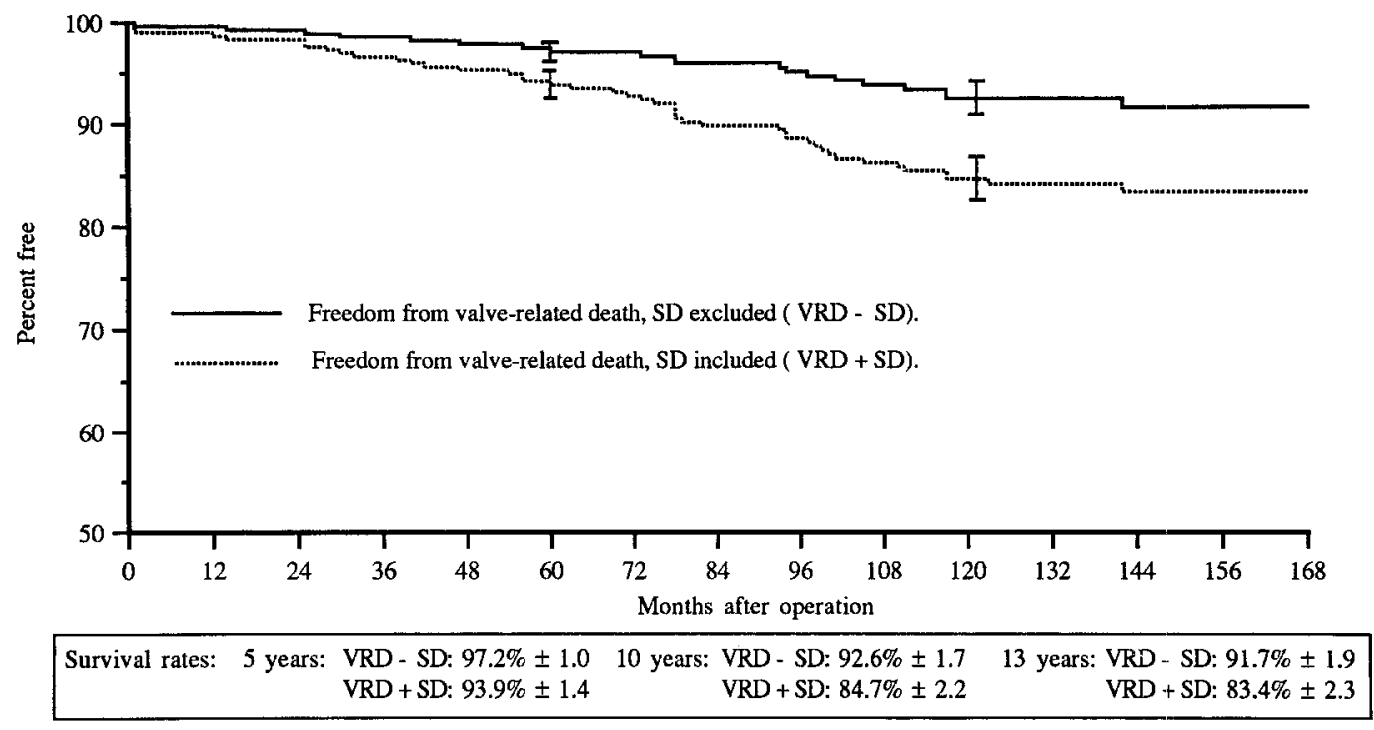

Fig. 5. Actuarial freedom from valve-related death $(V R D)$ with sudden death $(S D)$ being included or excluded from valve-related death.

various negative characteristics, some well known (atrial fibrillation, increased risk of atherosclerosis, and increased frequency of past cardiac operations) and possibly others that are unknown. Eliminating this risk factor from the multivariate analysis did not make others become significant. In other respects, the poorer survival for the AVR group (Fig. 3) was somewhat surprising and not in keeping with findings of most past studies. Only Kratz and colleagues ${ }^{11}$ showed similar findings. In the present study, this trend was caused by an increased incidence of various valve-related complications, which led to more frequent valve-related deaths, particularly for degenerative sclerosing valve disease. The increased sex ratio; the increased frequency of coronary artery disease, coronary artery bypass grafting, and hypertension; and the higher proportion of older patients ( $>70$ years) in the AVR group compared with the MVR and multiple VR groups together do not completely explain this point: the patient characteristics and the surgical technique used for AVR did not differ notably from what has previously been reported. Although a selection bias cannot be excluded, we perhaps missed some critical factors in the history or in the general, cardiac, and valvular state of these patients that could explain this discrepancy.

Sudden death and valve-related death. Above all, sudden death was linked with a low preoperative ejection fraction or with coronary artery disease, suggesting a non-valve-related cause. We agree with Butchart" that "it is illogical to attribute every sudden death in a prosthetic valve series to the prosthesis itself, particularly when a high proportion of the patients have coronary disease"; this realization led us to present our data with sudden deaths separately or integrated in valve-related deaths. Alcoholism was a risk factor for sudden death and for valve-related death probably because of anticoagulation-related hemorrhages.

The incidence of valve-related deaths was higher with small prostheses $(\leq 23 \mathrm{~mm})$, but small valves were used only for aortic replacements, and use of small valves was thus a demonstrated risk factor only in this category. Small diameter is significantly correlated with female sex, small body surface area, and increased age, but this does not fully explain the increased risk; the small prostheses may be submitted to higher forces that lead to paravalvular leaks and create turbulences in blood flow that favor thrombosis, embolisms, and vegetations. Alcoholism and a degenerative cause of valve disease were also independent factors of valve-related death but, importantly, age was not.

Cardiac non-valve-related death. Cardiac death remained the primary cause of death and was directly related to the degree of preoperative coronary disease, myocardial dysfunction, and cardiac enlargement despite surgical revascularization at the time of valve replacement. This emphasizes the need for early valvular operation. 


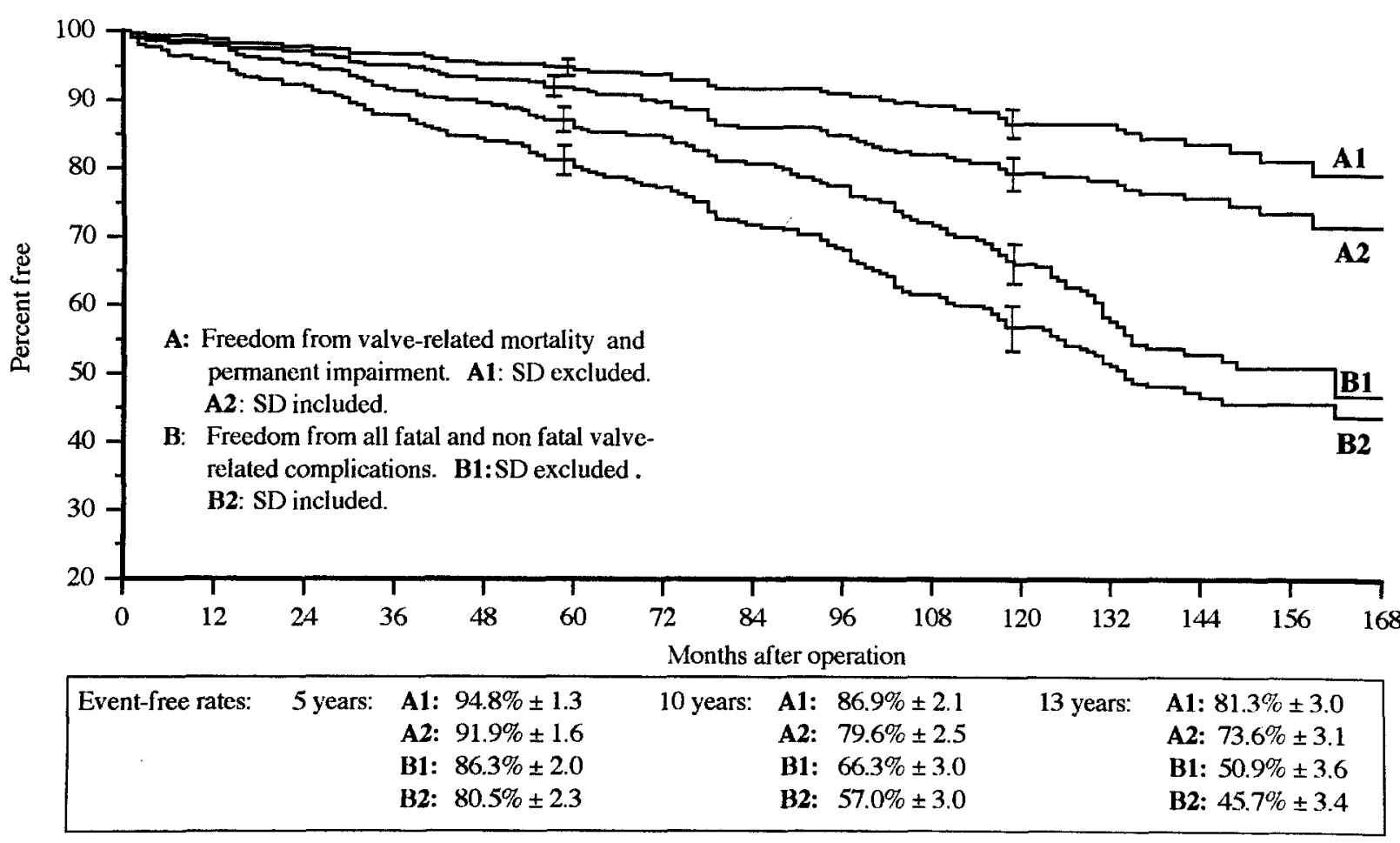

Fig. 6. Actuarial freedom from all valve-related complications and from combined valve-related mortality and permanent impairment. For each of these two endpoints two curves are showed, one including and the other excluding sudden death $(S D)$ as a valve-related complication.

Table X. Linearized rates (ranges) on valve-related complications after valve replacement with St. Jude Medical prosthesis in 11 published follow-up studies

\begin{tabular}{lc}
\hline & Rate (\%/pt-yr) \\
\hline Embolism & $0.5-3.5$ \\
Hemorrhage & $0.1-2.8$ \\
Valve thrombosis & $0.0-0.5$ \\
Endocarditis & $0.1-0.6$ \\
Paravalvular leaks & $0.1-0.8$ \\
Hemolytic anemia & $0.0-0.2$ \\
Reoperations & $0.1-0.9$ \\
Valve-related deaths & $0.5-1.3$
\end{tabular}

See text for references.

Functional improvement. For survivors the functional result was excellent and sustained with most of patients being in NYHA class I or II after 10 years. That $77 \%$ of the nonretired patients were professionally active has, of course, an important positive impact in socioeconomic terms.

Limitations of the study. Although we tried to minimize the effect of the retrospective collection of data by a thorough examination of hospital files and by precise questionnaires, events such as transient ischemic attacks, for example, may be missed and information on hemodynamic values and on anticoagulation control at the time of events was not complete. Differences in the definitions of endpoints made comparisons among studies difficult. The guidelines of The Society of Thoracic Surgeons and The American Association for Thoracic Surgery have only partially solved this problem, particularly concerning embolic events, valve-related hemorrhages, and sudden death. We used several definitions in the methods section that may not correspond to those used in other reports. Statistical power, when analyzing covariates in subgroups such as operative groups or types of valvular disease, was low because of small numbers of patients or events.

In conclusion, this study confirms that with St. Jude Medical valves, prosthesis-related complications are still common and sometimes dangerous. About $20 \%$ of patients, at 10 years, will be dead of valve-related causes or have a permanent impairment related to the prosthesis. The preoperative status of the patients is a major determinant of the long-term outcome. Anticoagulation should be op- 
timal and adapted to the individual patient taking into account the various risk factors for emboli and hemorrhages. In patients without complications the functional improvement is immediate, sustained, and warrants a normal professional life in the great majority of cases.

We thank the Swiss Office Fédéral de la Statistique for the information received on death certificates for some of our patients. Dr. Debétaz is infinitely grateful to his wife and children for their help and huge patience during all the time necessary to achieve this study.

\section{REFERENCES}

1. Kinsley RH, Antunes MJ, Colsen PR. St. Jude Medical valve replacement: an evaluation of valve performance. J Thorac Cardiovasc Surg 1986;92:349-60.

2. Burckhardt D, Striebel D, Vogt $S$, et al. Heart valve replacement with St. Jude Medical valve prosthesis: long-term experience in 743 patients in Switzerland. Circulation 1988; 78(Suppl):I18-24.

3. Myers ML, Lawrie GM, Crawford ES, et al. The St. Jude valve prosthesis: analysis of the clinical results in $815 \mathrm{implants}$ and the need for systemic anticoagulation. J Am Coll Cardiol 1989;13:57-62.

4. Arom KV, Nicoloff DM, Kersten TE, Northrup WF, Lindsay WG, Emery RW. Ten years' experience with the St. Jude Medical valve prosthesis. Ann Thorac Surg 1989; 47:831-7.

5. Arom KV, Nicoloff DM, Kersten TE, Northrup WF, Lindsay WG, Emery RW. Ten-year follow-up study of patients who had double valve replacement with the St. Jude Medical prosthesis. J Thorac Cardiovasc Surg 1989; 98:1008-16.

6. Nair CK, Mohiuddin SM, Hilleman DE, et al. Ten-year results with the St. Jude Medical prosthesis. Am J Cardiol 1990;65:217-25.

7. Lund O, Knudsen MA, Pilegaard HK, Magnussen K, Nielsen TT. Long-term performance of Starr-Edwards Silastic ball valves and St. Jude Medical bi-leaflet valves. Eur Heart J 1990;11:108-19.

8. Vogt S, Hoffmann A, Roth J, et al. Heart valve replacement with the Björk-Shiley and St. Jude Medical prostheses: a randomized comparison in 178 patients. Eur Heart J 1990; 11:583-91.

9. Czer LSC, Chaux A, Matloff JM, et al. Ten-year experience with the St. Jude Medical valve for primary valve replacement. J Thorac Cardiovasc Surg 1990;100:44-55.

10. Smith JA, Westlake GW, Mullerworth $\mathrm{MH}$, Skillington PD, Tatoulis J. Excellent long-term results of cardiac valve replacement with the St. Jude Medical valve prosthesis. Circulation 1993;88(pt 2):II49-54.

11. Kratz JM, Crawford FA, Sade RM, Crumbley AJ, Stroud MR. St. Jude prosthesis for aortic and mitral valve replacement: a ten-year experience. Ann Thorac Surg 1993;56:462-8.

12. Fernandez J, Laub GW, Adkins MS, et al. Early and latephase events after valve replacement with the St. Jude Medical prosthesis in 1200 patients. J Thorac Cardiovasc Surg 1994;107:394-407.

13. Khan S, Chaux A, Matloff JM, et al. The St. Jude Medical valve: experience with 1000 cases. J Thorac Cardiovasc Surg 1994;108:1010-20.

14. Nakano K, Koyanagi H, Hashimoto A, et al. Twelve years' experience with the St. Jude Medical valve prosthesis. Ann Thorac Surg 1994;57:697-702.

15. Aoyagi S, Oryoji A, Nishi Y, Tanaka K, Kosuga K, Oishi K. Long-term results of valve replacement with the St. Jude Medical valve. J Thorac Cardiovasc Surg 1994;108:1021-9.

16. Isomura $T$, Hisatomi $K$, Hirano A, Kosuga $K$, Ohishi $K$. The St. Jude Medical prosthesis in the mitral position. Eur J Cardiothorac Surg 1994;8:11-4.

17. Ibrahim M, O'Kane H, Cleland J, Gladstone D, Sarsam M, Patterson C. The St. Jude Medical prosthesis: a thirteenyear experience. J Thorac Cardiovasc Surg 1994;108:22130.

18. Baudet EM, Puel V, McBride JT, et al. Long-term results of valve replacement with the St. Jude Medical prosthesis. J Thorac Cardiovasc Surg 1995;109:858-70.

19. Hjelms E. Escape of a leaflet from a St. Jude Medical prosthesis in the mitral position. $\mathbf{J}$ Thorac Cardiovasc Surg 1983;31:310-2.

20. Ziemer G, Luhmer I, Oelert H, Borst HG. Malfunction of a St. Jude Medical heart valve in mitral position. Ann Thorac Surg 1982;33:391-4.

21. Edmunds LH, Clark RE, Cohn LH, Miller DC, Weisel RD. Guidelines for reporting morbidity and mortality after cardiac valvular operations. Ann Thorac Surg 1988;46: 257-9.

22. Bodnar E, Butchart EG, Bamford J, Besselaar AMPH, Grunkemeier GL, Frater RWM. Proposal for reporting thrombosis, embolism and bleeding after heart valve replacement. J Heart Valve Dis 1994;3:120-3.

23. McGoon DC. The risk of thromboembolism following valvular operations: How does one know? J Thorac Cardiovasc Surg 1984;88:782-6.

24. Mitchell RS, Miller DC, Stinson EB, et al. Significant patientrelated determinants of prosthetic valve performance. J Thorac Cardiovasc Surg 1986;91:807-17.

25. Lindblom D. Long-term clinical results after mitral valve replacement with the Björk-Shiley prosthesis. J Thorac Cardiovasc Surg 1988;95:321-33.

26. Eberlein U, von der Emde J, Rein J, Esperer HD. Thromboembolic and bleeding complications after mitral valve replacement. Eur J Cardiothorac Surg 1990;4:605-12.

27. Horstkotte D, Schulte HD, Bircks W, Strauer B. Unexpected findings concerning thromboembolic complications and anticoagulation after complete 10 year follow-up of patients with St. Jude Medical prostheses. J Heart Valve Dis 1993;2:291301.

28. Kopf GS, Hammond GL, Geha AS, Elefteriades J, Hashim SW. Long-term performance of the St. Jude Medical valve: low incidence of thromboembolism and hemorrhagic complications with modest doses of warfarin. Circulation 1987; 76(Suppl):III132-6.

29. Gohlke-Bärwolf C, Acar J, Oakley C, et al. Study group of the working group on valvular heart disease of the European Society of Cardiology: guidelines for prevention of thromboembolic events in valvular heart disease. Eur Heart J 1995; 16:1320-30.

30. Butchart EG. The significance of sudden and unwitnessed death after heart valve replacement. J Heart Valve Dis 1994;3:1-4. 


\section{Appendix}

The following table shows the risk factors screened by log-rank test for each valve-related complication, for overall mortality, for valve-related death, sudden death, cardiac non-valve-related death, and for combined events (mortality and morbidity, mortality and perma- nent morbidity) with and without sudden death included. After this first screening, we tested, when needed, one or more specific physiopathologic anomalies against the others. The same was done for the different causes of valve disease or for the distinct groups of valvular replacement.

\begin{tabular}{|c|c|}
\hline Variables & Categories \\
\hline Sex & Male/female \\
\hline History of prior cardiac operation & Absent/present \\
\hline History of prior embolism & Absent/present \\
\hline Diabetes before operation & Absent/present \\
\hline Presence of cardiovascular risk factors & Yes/no \\
\hline Presence of coronary disease* & Absent/present \\
\hline Severity of coronary disease $\dagger$ & Absent/monotruncal/bitruncal/tritruncal or common trunk \\
\hline $\begin{array}{l}\text { Coronary arterial bypass grafting additional } \\
\text { to the valvular replacement }\end{array}$ & Absent/present \\
\hline Other additional procedures & Absent/present \\
\hline Chronic alcohol abuse before operation & Absent/present \\
\hline Emergency operation & Yes/no \\
\hline Cardiac rhythm before operation & Sinusal/atrial fibrillation \\
\hline Cardiac rhythm, end of hospitalization $\neq$ & Sinusal/atrial fibrillation \\
\hline $\begin{array}{l}\text { Physiopathologic anomaly (for single valve } \\
\text { replacement only) }\end{array}$ & $\begin{array}{l}\text { Mitral regurgitation/mitral stenosis/mixed mitral disease/aortic } \\
\text { regurgitation/aortic stenosis/mixed aortic disease }\end{array}$ \\
\hline Cause of valve disease & $\begin{array}{l}\text { Rheumatic/congenital/endocarditic/degenerative/myxomatous/ } \\
\text { prosthetic dysfunction/ischemic/aortic root disease }\end{array}$ \\
\hline $\begin{array}{l}\text { Associated tricuspid valvulopathy (structural } \\
\text { or functional, operated or not) }\end{array}$ & Absent/present \\
\hline $\begin{array}{l}\text { Cardiac failure as single indication for oper- } \\
\text { ation }\end{array}$ & Yes/no \\
\hline Syncope as single indication for operation & Yes/no \\
\hline Angor as single indication for operation & Yes/no \\
\hline Acute preoperative bacterial endocarditis & Yes/no \\
\hline NYHA class & NYHA I-II/NYHA III-IV and NYHA I-III/NYHA IV \\
\hline Operation & AVR/MVR/multiple VR \\
\hline Age $(y r)$ & $<45 / \geq 45$ and $<60 / \geq 60$ \\
\hline Cardiothoracic index & $\leq 0.50 />0.50$ \\
\hline Ejection fraction (\%) & $<50 / \geq 50$ \\
\hline Cardiac index $\left(\mathrm{L} / \mathrm{min} / \mathrm{m}^{2}\right)$ & $<2.5 / \geq 2.5$ \\
\hline Left ventricular end-diastolic index $\left(\mathrm{ml} / \mathrm{m}^{2}\right)$ & $<100 / \geq 100$ \\
\hline Left ventricular end-systolic index $\left(\mathrm{ml} / \mathrm{m}^{2}\right)$ & $<45 / \geq 45$ \\
\hline Mean pulmonary arterial pressure $(\mathrm{mm} \mathbf{H g}$ ) & $<30 / \geq 30$ \\
\hline Pulmonary wedge pressure $(\mathrm{mm} \mathrm{Hg})$ & $<20 / \geq 20$ \\
\hline Prosthesis diameter $(\mathrm{mm})$ & $\leq 23 />23$ and $<27 / \geq 27$ \\
\hline
\end{tabular}

*The presence or absence of coronary disease was defined by history of prior myocardial infarction or prior coronary artery bypass grafting or by the presence of significant $(>50 \%)$ stenosis of a major coronary artery on the preoperative arteriogram.

$†$ Severity of coronary disease: only patients with preoperative coronary disease were considered to do the classification into monotruncal/bitruncal/tritruncal Only stenoses of more than $50 \%$ were considered.

¥This variable was not used to analyze endpoints including in-hospital events (such as overall mortality). 